\title{
Study on application and performance of OPPC under ice-phased condition
}

\author{
Yi $\mathrm{AN}^{1, a}$ \\ ${ }^{1}$ Information and Telecommunication Company of Shanxi Electric Power Corporation, Taiyuan 031000, China
}

\begin{abstract}
The optical fiber composite overhead line (OPPC) combines electricity transmission and information transmission, is used increasingly widely in the electric power system, further broadening the application area of our country's special cable in the meantime. In heavy ice-phased regions, the designing parameters and technical requirements should be of higher standards, or it will directly affect the safety and stability of electric communication system's operation. Therefore, OPPC under ice condition performance changes should cause enough attention. This article proposes simulation test of OPPC under ice-cladding condition, basing on which the mechanical properties and light transmission performance were calculated and analyzed. Then it comes to a conclusion that the ice-cladding has a variety of impact on OPPC in the stress and strain of fiber optic cable, optical transmission performance, residual RTS and other related elements. The test results show that the corresponding tension values under ice thickness would change and should be taken seriously into consideration when discussing the application of OPPC line under ice-phased condition.
\end{abstract}

\section{Introduction}

OPPC is developed in recent years gradually a kind of new type of electric power special fiber optic cable, and power transmission and double function of communication. And it has been widely used in related to OPGW. Compared with special ADSS optical cable, OPPC has many unique advantages, which make it in our country granted a broad application prospect in low voltage power distribution network. The emergence of OPPC and put into use, further broaden the application area of our country's special cable. Used special OPPC new technology has solved the power cable in electric corrosion, the disadvantages of theft, struck by lightning, provide low voltage intelligent power grid automation development in the future with optical fiber communication channel.

OPPC has been used in domestic voltage level of $220 \mathrm{kV}$ and below the line, to the reformation and the new line, it cannot erect OPGW, ADSS and ordinary optical cable lines, providing the effective solution. According to incomplete statistics, the country already has more than 4 , $000 \mathrm{~km}$ of OPPC related voltage grade line application, in addition to the regular meteorological conditions and geographical conditions in application, especially at high altitudes, where the alpine areas and mountain areas, high temperature region were applied. But when it is applied in repeat ice should fully consider the ice to the influence of OPPC, otherwise the continuous low temperature sleet freezing disasters in the atmosphere, will cause transmission lines ice break down accident, seriously affecting the safe and stable operation of power grid China's vast territory. Meteorological condition difference is bigger, ice is inevitable, and thus the safety of the product and the safety of engineering application is particularly significant

Transmission line conductor ice coating side of the issue has caused the attention and research, but OPPC and conductor is different, which is formed in the element of optical fiber composite phase line of a new type of electric power special optical cable, mainly consisting of optical unit and wire unit. OPPC transmission performance by external force time unit is not affected.

Using laboratory simulation environment, a practical engineering application of OPPC ice simulation experiment was carried out, based on the certain condition of ice thickness OPPC performance of theoretical calculation and experimental study, analysis the influence of ice coating on properties of OPPC.

\section{Simulation test description of ice- phase condition}

Trials to select a voltage level of transmission line engineering construction of OPPC as sample, the structure of ground structure, diameter $17.50 \mathrm{~mm}$, nominal tensile strength of $55.7 \mathrm{kN}$ ice test ice thickness should be set according to the local weather condition. Table 1 shows the test sample application area of ice design weather conditions, climate conditions usually ice

a Corresponding author: 525492887@qq.com 
thickness is generally $10 \mathrm{~mm}$, considering the special situation, and design value should be adjusted.

Table 1. Ice design weather conditions.

\begin{tabular}{|c|c|c|c|c|}
\hline No. & Meteorological parameters & Temperature $\left({ }^{\circ} \mathrm{C}\right)$ & Wind speed(m/s) & Ice thickness(mm) \\
\hline 1 & Lowest temperature & -38 & 3 & 0 \\
\hline 2 & Average temperature & -10 & 28 & 0 \\
\hline 3 & Fastest wind speed & -5 & 12 & 11 \\
\hline 4 & Ice-phased & -5 & 0 & 0 \\
\hline 5 & Highest temperature & 38 & 0.892 & \\
\hline 6 & The proportion of ice & & & 0 \\
\hline
\end{tabular}

Table 2. Different ice thickness and tension comparison.

\begin{tabular}{|c|c|c|c|c|}
\hline Parameters & \multicolumn{4}{|c|}{ Calculation methods } \\
\hline Ice thickness $(\mathrm{mm})$ & 10 & 18 & 26 & 34 \\
\hline Ice weight $(\mathrm{kg} / \mathrm{m})$ & 0.7652 & 1.9875 & 3.4750 & 5.8782 \\
\hline Tension(kN) & 15.833 & 25.767 & 37.684 & 51.950 \\
\hline
\end{tabular}

A lot of ice classification, according to the formation of ice, nature, appearance, etc. There are several classified methods, choose the cylindrical ice to facilitate the test. Ice density is $0.9 \mathrm{~g} / \mathrm{cm} 3$, preliminary work for $16 \%$ RTS $=8.912 \mathrm{kN}(\mathrm{RTS})=55.7 \mathrm{kN}$ o due to the actual line biggest span is about $269 \mathrm{~m}, 269 \mathrm{~m}$ to $30 \mathrm{~m}$ conversion laboratory will test file is apart from the corresponding ice conditions bligh. Calculate the $10 \mathrm{~mm}$, $20 \mathrm{~mm}, 30$ and $40 \mathrm{~mm} \mathrm{~mm}$ corresponding weight of ice and ice thickness by tension values, are shown in table 2 and table 3 . As you can see, $10 \mathrm{~mm}$ and $20 \mathrm{~mm}$ when the thickness of ice cable tension by RTS $30.1 \%$ and $30.1 \%$ respectively RTS, the factory inspection qualified products can meet the test requirements, when the ice thickness of $30 \mathrm{~mm}$, tension cable suffered $72.4 \%$ RTS, need a validation test.

Ice experiment plan: prepare OPPC samples of $100 \mathrm{~m}$, exert tension span $30 \mathrm{~m}$, on both ends of the concatenated fiber length $1000 \mathrm{~m}$; Calculation of $30 \mathrm{~m}$ span, different thickness ice weight $(\mathrm{kg} / \mathrm{m})$ are shown in table 3, exert tension 16\% RTS $8.912 \mathrm{kN}$ operation; Using simulated ice cover, points a few times evenly coated heavy, maintain after the completion of $96 \mathrm{~h}$, during the test record of optical fiber attenuation, force value, the change of cable length, etc.

\section{Simulation test results under $20 \mathrm{~mm}$}

\subsection{Optical fiber attenuation test}

Experiment using the ice line fiber 6.652 single-mode fiber, test using OTDR $1550 \mathrm{~nm}$ wavelength window.
$1550 \mathrm{~nm}$ wavelength in the process of test, the simulated ice about $72 \mathrm{~h}$, fiber optic additional attenuation increases gradually, the surge in about 0.035 $\mathrm{dB} / \mathrm{km}$, which will affect the transmission performance of the fiber. $96 \mathrm{~h}$ after removing ice, additional attenuation fiber recovery to the initial state before the ice.

Test attenuation curve is shown in figure I, you can see, in the process of ice for a long time, the cable tension, make its produce strain, causes the fiber in the OPPC released in full, fiber began to stress, the additional damping increase.

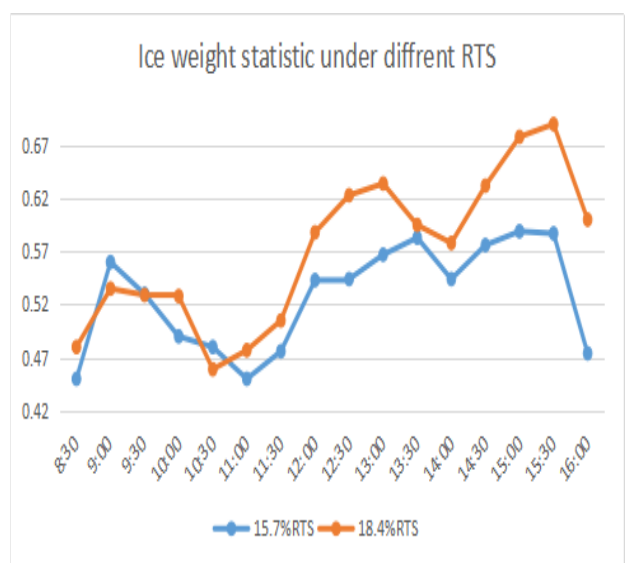

(a) 


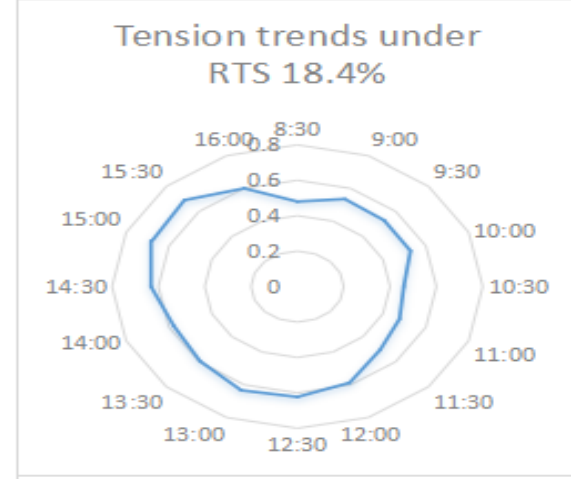

(b)

Figure 1. Ice weight statistics under different RTS and related tension analysis.

\subsection{Stress strain test}

Stress and strain test is used to determine its condition at a given load mechanical properties and fiber attenuation changes. Bligh for $30 \mathrm{~mm}$ thickness of ice conditions, in the case of $40 \% 40 \%$ RTS and RTS tensile force of divination for ice before and after the stress and strain test of the sample. Fiber tensile load and performance shall comply with and the provisions of the corresponding optical fiber length is not less than $100 \mathrm{~m}$.

Stress and strain test is used to determine its condition at a given load mechanical properties and fiber attenuation changes. Bligh for $30 \mathrm{~mm}$ thickness of ice conditions, in the case of $40 \% 40 \%$ RTS and RTS tensile force of divination for ice before and after the stress and strain test of the sample. Fiber tensile load and performance shall comply with and the provisions of the corresponding optical fiber length is not less than $100 \mathrm{~m}$.

(1) RTS tensile stress strain test

Acceptance criteria: $40 \%$ RTS tension, fiber optic strain, optical fiber no additional damping.

Test results: ice before the test curve as shown in figure II, after the ice test curve is shown in Figure III. Figure III and figure II contrast can be seen that the top $40 \%$ RTS ice force, fiber optic strain, optical fiber without additional attenuation; Ice after RTS pull down $40 \%$, fiber optic strain, but there are additional two optical attenuation is greater than $0.03 \mathrm{~dB}$, additional one optical attenuation is $0.05 \mathrm{~dB}$, the ice has certain influence on the transmission performance of the fiber.

(2) RTS tensile stress and strain test

Acceptance criteria: RTS pulled in $60 \%, 0.25 \%$, fiber optic strain optical fiber attenuation core 0.05 , additional tension after cancel, no obvious residual additional fiber attenuation.

Test results: ice before the test curve as shown in figure 4 , the ice after the test curve . Contrast, ice OPPC samples before fiber optic strain, fiber optic attenuation core 0.05 , additional tension after cancel, no obvious residual additional fiber attenuation; Ice OPPC samples after fiber optic strain, with a single fiber $40 \%$ RTS tensile stress and strain test of the same root fiber, additional attenuation is beyond 0.05 , after pulling force to cancel, no obvious residual additional fiber attenuation.

(3)30 $\mathrm{mm}$ ice OPPC cable length change test
Figure 6 to $30 \mathrm{~mm}$ thickness of ice conditions blight OPPC cable length change curve, fiber optic cable length before and after the ice by initial elongation of $28.50 \mathrm{~m}$ to $28.50 \mathrm{~m}$, long after the ice to maintain phase line after a slight fluctuation change value tends to be stable, the length of $28.62 \mathrm{~m}$ and wood remains unchanged. $96 \mathrm{~h}$ after removing ice, sample length is $28.62 \mathrm{~m}$.

\subsection{After the ice tensile performance}

After freeze disaster through the atmosphere, easy to pour tower bolt accidents, accident the main reason is that conductor ice coating thickness more than design ice thickness, ice produce longitudinal unbalanced than tower design load of experimental study on ice thickness exceeds design ice thickness of OPPC the effects of tensile performance.

After $30 \mathrm{~mm}$ thickness ice, tensile force test for OPPC tension RTS $95 \%$ and lasts $1 \mathrm{~min}$. In the process of test, found that while maintaining time to 20, "pa" noise from the OPPC, tension not reduce at this time, still remained at $95 \%$ RTS until the end of the test, after dissection found cable outer single fracture, adjacent to the outer aluminum alloy wire, may cause broken stocks, as shown in figure III, fracture mono-filament largest number 6, at least one root. Through the shape and structure of the breaking point found for transverse tensile fracture. That ice thickness of $30 \mathrm{~mm}$ beyond the OPPC sample ice thickness design value, can lead to tensile performance drop. Easy to broken cable accidents.

\section{Simulation test results under $40 \mathrm{~mm}$}

According to $40 \mathrm{~mm}$ thickness of ice conditions in table 3 groundwater calculation of tension and ice thickness data conversion, wooden article has carried on the laboratory span $40 \mathrm{~mm}$ ice simulation test, tension is $54.56 \mathrm{kN}$, OPPC suffered 98.0\% RTS, approaching OPPC rated tensile strength values. Test using simulated ice points several times evenly coated. Covering all maintain after the completion of $96 \mathrm{~h}$. Observe the change of the sample during the test.

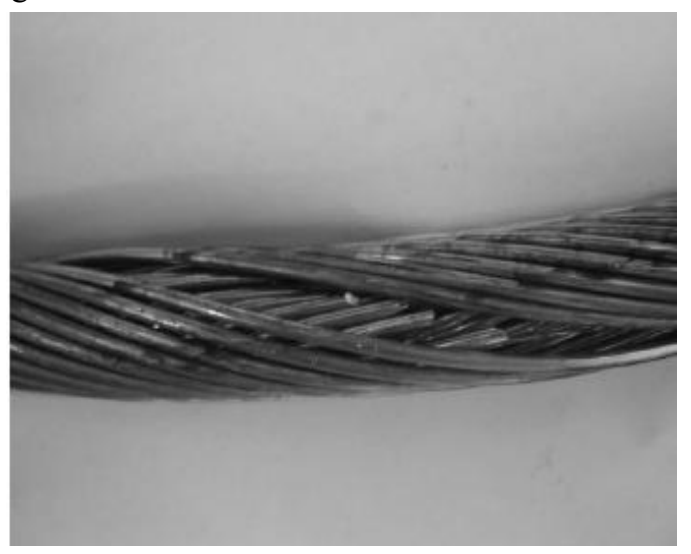

(a) 


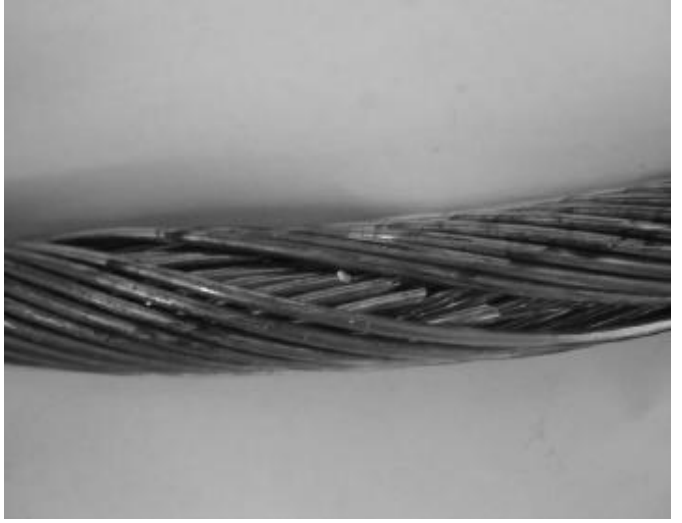

(b)

Figure 2. Outer layer fracture of tested OPPC.

During the ice to maintain about $48 \mathrm{~h}$, OPPC outer a mono-filament appear rupture, adjacent outer monofilament fracture all at the same time, as shown in figure 2 , fiber tensile strength is reduced, the experiment is over.

Because the OPPC samples during the ice test by heavy far beyond can withstand the design value of its own. Therefore mono-filament fracture. Illustrate the OPPC samples can't bear more than $40 \mathrm{~mm}$ and the thickness of the ice.

\section{Conclusion}

By stress strain test, the ice before the fiber attenuation curve is smooth and in the range of qualified, ice after 96 $h$, fiber optic attenuation increases obviously, the individual fiber beyond the standard requirements, ice that not only have an effect on fiber mechanical properties, especially the long fiber before and after the ice and strain, causes the fiber in the OPPC released in full, fiber began to stress, additional attenuation increases, resulting in ice impact on optical fiber attenuation.
Through the same sample in $30 \mathrm{~mm}$ and $40 \mathrm{~mm}$ compared the different thickness of ice conditions blight test, the sample during the end of the $40 \mathrm{~mm}$ ice test time is not the single fracture. Due to $40 \mathrm{~mm}$ ice simulation test of OPPC with $98.0 \%$ by tension RTS, approaching OPPC rated tensile strength value, therefore, the sample is hard to bear for a long time so the thickness of ice, illustrate the OPPC samples can't bear more than $40 \mathrm{~mm}$ and the thickness of the ice.

In addition, based on tensile performance test in tension 95\% RTS mono-filament fracture phenomenon, maintaining time of test samples under $30 \mathrm{~mm}$ thickness of ice is just in the OPPC tensile performance of critical state, and $30 \mathrm{~mm}$ ice thickness corresponding tension OPPC suffered $72.4 \%$ RTS, therefore, considered in repeat ice OPPC under ice condition, accounting should be corresponding tension values under ice thickness, if the tension is greater than $70 \%$ RTS, should further through the test of OPPC tensile properties and stress and strain properties.

\section{References}

1. Jinesh Varia;Satia Munerze.OPPC fiber test and application study.Science and Electronic Equipment Press, (2009)

2. Mathew Perry.Textile pattern design based on changed-multi-rules of climate system. 2013 IEEE International Symposium on Instrument \& Measurement, 29-33.

3. Oxford,RL.Optical fiber research:performance study under extreme condition .Newbury House /Harper Collins,NY, (2008)

4. Andrew D.Cohen.Electric optical communication transmision's path selection. EI Journal Assemble on 2009

5. Rod Ellis.Ice-phased altimation influences on OPPC linear parting.EI Journal Assemble on 2009. 